\title{
Patient Activation as a Pathway to Shared Decision-making for Adults with Diabetes or Cardiovascular Disease
}

\author{
Bing Ying Poon, PhD (D), Stephen M. Shortell, PhD, MPH, MBA, and Hector P. Rodriguez, \\ $\mathrm{PhD}, \mathrm{MPH}$
}

School of Public Health, University of California Berkeley, Berkeley, CA, USA.

\begin{abstract}
BACKGROUND: Shared decision-making (SDM) is widely recognized as a core strategy to improve patient-centered care. However, the implementation of SDM in routine care settings has been slow and its impact mixed.
\end{abstract}

OBJECTIVE: We examine the temporal association of patient activation and patients' experience with the SDM process to assess the dominant directionality of this relationship.

DESIGN: Patient activation, or a patients' knowledge, skills, and confidence in self-management, was assessed using the 13-item Patient Activation Measure (PAM). Patient-reported assessment of the SDM process was assessed using the 3-item CollaboRATE measure. Patients at 16 adult primary care practices were surveyed in 2015 and 2016 on PAM $(\alpha=0.92)$, CollaboRATE $(\alpha=$ 0.90), and demographics. The relationship between PAM and CollaboRATE was estimated using a cross-lagged panel model with clustered robust standard errors and practice fixed effects, controlling for patient characteristics.

PARTICIPANTS: 1222 adult patients with diabetes and/ or cardiovascular disease with survey responses at baseline (51\% response rate) and a 1-year follow-up (73\% response rate).

RESULTS: PAM (mean 3.27 vs 3.28 on a range of 1 to 4; $p=0.082$ ) and CollaboRATE (mean 3.62 vs 3.63 on a range of 1 to $5 ; p=0.14$ ) did not change significantly over time. In adjusted analyses, the path from baseline PAM to follow-up CollaboRATE ( $\beta=0.35 ; p<0.0001)$ was stronger than the path from baseline CollaboRATE to follow-up $\operatorname{PAM}(\beta=0.04 ; p=0.001)$.

CONCLUSIONS: The relationship between patient activation and patients' experiences of the SDM process is bidirectional, but dominated by baseline patient activation. Rather than promoting the use of SDM for all patients, healthcare organizations should prioritize interventions to promote patient activation and engage patients with relatively high activation in SDM interventions.

KEY WORDS: patient-centered care; patient activation; shared decisionmaking; patient-physician communication; patient-physician relationship.

Prior Presentations Preliminary results from this study have been previously presented at the 2018 NRSA Research Trainees Conference and the 2018 AcademyHealth Annual Research Meeting.

Received April 3, 2019

Accepted September 11, 2019

Published online October 23, 2019
J Gen Intern Med 35(3):732-42

DOI: $10.1007 / \mathrm{s} 11606-019-05351-6$

(C) Society of General Internal Medicine 2019

\section{INTRODUCTION}

Cardiovascular disease (CVD) is the leading cause of death in the USA and often co-occurs with diabetes. These two conditions account for $17 \%$ and $24 \%$ of national expenditures ${ }^{1-3}$. The effective management of diabetes and CVD depends crucially on treatment adherence ${ }^{4-7}$, but many patients with diabetes and/or CVD are not adherent to prescribed treatment plans. The mean medication adherence rate among patients with cardiovascular disease across 129 studies was $76.6 \%$ while the mean medication adherence rate among adult patients with diabetes across 23 studies was $67.5 \%^{8}$.

Shared decision-making (SDM) is a collaborative process in which patients and physicians exchange information about patient preferences and treatment options and tradeoffs to arrive at treatment decisions ${ }^{9,} 10$. SDM for patients with diabetes and/or CVD has the potential to improve adherence because patients are better able to adhere to treatment plans that were collaboratively developed with their physicians, and are more likely to reflect their motivations, abilities, and physical environment ${ }^{11}$. Despite SDM's potential for improving care, not all patients want to engage in medical decision-making ${ }^{12}$. Older, less healthy, and less educated patients tend to prefer less active roles in medical decision-making ${ }^{13}$ but these same patients are also most likely to benefit from engaging in shared decisions with physicians ${ }^{14}$.

Patient preferences for engaging in treatment decisions are dynamic and can increase with improved knowledge and self-efficacy, where self-efficacy is confidence in one's capabilities ${ }^{15,16}$. Patient activation, or a patient's selfassessment of knowledge, skills, and confidence to manage their own health ${ }^{17}$, may be an important precursor to SDM. Patient activation and SDM have both been associated with improved outcomes among patients with diabetes and/or cardiovascular disease ${ }^{11,18,19}$. Patient activation and patients' experiences of SDM are known to be associated, but the dominant direction of this association is unclear ${ }^{20,21}$. In this study, we aim to untangle the temporal relationship 
between patient activation and SDM among adult patients with diabetes and/or CVD.

We developed hypotheses about the connections between patient activation and patients' experiences of SDM using an interactionist perspective on communication, which stipulates that the clinical encounter is jointly produced by the patient and the physician in a bidirectional relationship ${ }^{22}$. Specifically, we used survey data from adult patients with diabetes and/ or CVD to examine the following three hypotheses:

1. Better baseline experiences of SDM are associated with higher patient activation at follow-up.

2. Higher baseline patient activation is associated with better experiences of SDM at follow-up.

3. The relationship between patient activation and experiences of SDM is dominated by baseline patient activation.

\section{METHODS}

\section{Data}

Patient survey and clinical data linked to practice survey data from the ACTIVATE study ${ }^{21}$ were analyzed. Two large accountable care organizations (ACOs) participated in the ACTIVATE study: Advocate Health Care in the greater Chicago, IL, area and HealthCare Partners in the greater Los Angeles, CA, area. Both are large healthcare systems that participated in the Medicare Shared Savings program, which provides incentives for increasing patient involvement in care to reduce costs and improve outcomes. A 39-item survey on organizational practices of patient involvement was developed based on prior research and a review of the literature ${ }^{23}$. The survey was administered to the clinical or practice leader at each of the 44 practices at Advocate and 27 practices at HealthCare Partners. Respondents indicated the extent to which the physicians practiced each of the 39 activities, from not at all $(0 \%)$ to all physicians always (100\%). Eight practices from each ACO were randomly selected for the primary study based on results from this survey: four from the top quartile of the distribution of adoption of organizational practices and four from the bottom quartile. Differences in the characteristics of practices with high vs low adoption of patient engagement strategies have been previously described ${ }^{24}$.

Within each of the 16 practice sites, adult patients were sampled if they had at least one visit to the site in the year before each survey, if they had a diagnosis of diabetes and/ or CVD, if they were over 18 years old, and if they spoke English and/or Spanish for the purposes of completing the patient survey. Patients were surveyed between April and September 2015 (baseline) and again between May and August 2016 (follow-up). The institutional review board of the University of California, Berkeley approved the study protocol prior to data collection.

\section{Sample}

From an initial sampling frame of 4368 patients, there was a $51 \%$ response rate at baseline with 2192 non-respondents and 2176 respondents. Of the 2176 baseline respondents, 400 switched health plans or passed away, so were excluded. Another 485 patients did not respond to the follow-up survey for a response rate of $73 \%$ with 1291 respondents. The range of baseline patient survey response rates across 16 sites is 38 to $62 \%$ with a median of $51 \%$ at low adoption sites and a median of $52 \%$ at high adoption sites. Among baseline respondents, the follow-up response rates ranged from 68 to $80 \%$ with a median of $75 \%$ at low adoption sites and a median of $73 \%$ at high adoption sites. Of the 1291 respondents, 69 were excluded for missing key study variables. The final analytic sample includes 1222 patients with baseline and follow-up surveys and data for key study variables. Electronic health record (EHR) data on patient demographics, insurance status, and comorbidities were integrated with the survey data. The flowchart for this sample selection process is shown in Appendix Table 3.

\section{Measures}

The main independent variable is the short-form 13-item Patient Activation Measure (PAM), a measure of patients' skill, knowledge, and confidence in self-management. Patients were asked to indicate their level of agreement with 13 statements, such as "I am confident that I can take actions that will help prevent or minimize some symptoms or problems associated with my health condition," "I understand the nature and causes of my health condition," and "I know the different medical treatment options available for my health condition." See Appendix for a full description of this measure. Patient responses varied from (1) Strongly disagree to (4) Strongly agree. As PAM has been well validated as a unidimensional measure ${ }^{17,25-30}$, a composite PAM score $(\alpha=0.92)$ was calculated based on the half-scale rule, where at least half of the items comprising the measure have to be complete in order for a score to be calculated ${ }^{31}$.

The outcome measure is patients' experiences of SDM using Elwyn's CollaboRATE measure. Patients were asked to indicate the level of effort made in response to three questions: "How much effort was made to help you understand your health issues," "How much effort was made to listen to things that matter most to you about your health issues," and "How much effort was made to include what matters most to you in choosing what to do next." Patient responses varied from (1) No effort to (5) Every effort. A composite CollaboRATE score $(\alpha=0.90)$ was calculated based on the average of responses to these three questions using the half-scale rule. 
While CollaboRATE had a high reliability in our sample and is a "fast and frugal" measure that can be easily implemented in practice ${ }^{32}$, we also assessed our model using the 11item Patient Assessment of Chronic Illness Care (PACIC) because PACIC is a general measure of the quality of chronic illness care and is more widely used ${ }^{33}$. Of the 11 items, it includes three items on SDM: "I was helped to set specific goals to improve my eating or exercise," "I was helped to make a treatment plan that I could carry out in my daily life," and "I was helped to plan ahead so I could take care of my condition even in hard times." Patient responses varied from (1) Never to (4) Always. A composite PACIC score $(\alpha=0.91)$ was calculated based on the half-scale rule.

A comorbidity count (range $=0$ to 15 ) was calculated as a sum of the number of comorbid medical conditions documented in the EHR data, including health failure, atherosclerosis, aortic aneurysm, aortocoronary bypass, hypertension, asthma, emphysema, chronic obstructive pulmonary disease, mood disorders, other nonorganic psychoses, anxiety, adjustment reaction, and depression. English language proficiency was self-assessed in patient surveys.

\section{Statistical Analyses}

We compared patients included and excluded from the analytic sample using Wilcoxon rank-sum tests for categorical variables and chi-square tests for continuous variables. Changes over time in patient activation and patients' experience of SDM were assessed in the final sample using chi-square tests.

The relationship between patient activation and patients' experience of SDM was examined as a cross-lagged panel model consisting of simultaneous multivariable linear regressions $^{34,35}$. This approach allows for the simultaneous estimation of the association between patient activation at baseline and patients' experience of SDM at follow-up and the association between patients' experience of SDM at baseline and patient activation at follow-up. At baseline, the correlation between PAM and CollaboRATE was assessed through a latent variable. At follow-up, the correlation between PAM and CollaboRATE was assessed through residuals. We controlled for patient age, race, sex, education, insurance, English proficiency, and number of comorbidities. The model was fit using quasi-maximum likelihood estimation to account for non-independence of errors within practice clusters ${ }^{36}$ and practice fixed effects were included to account for time invariant differences between practices. The analyses were conducted using the gsem command on Stata 15.0 (Stata Corp., College Station, TX).

\section{Sensitivity Analyses}

We assessed the robustness of our results by restricting the sample to patients who answered all PAM and CollaboRATE items at both baseline and follow-up and re-estimating the model. To check for nonlinearity in relationships conditional on baseline patient activation, we re-estimated the model assessing the moderation of PAM on the path from PAM on CollaboRATE, the path from CollaboRATE on PAM, and the paths connecting baseline values and follow-up values for patient activation and SDM. To assess the robustness of our results when considering multiple dimensions of patients' experiences of chronic care beyond SDM, we re-estimated the model using PACIC in place of CollaboRATE.

\section{RESULTS}

Patients included in the sample were more likely to be over 65 (58\% vs $51 \% ; p=0.0001)$ and female $(57 \%$ vs $52 \% ; p=$ 0.018 ) with more comorbidities (mean 5.9 vs $5.5 ; p=$ 0.0005) compared with excluded patients (Table 1). PAM levels (baseline mean $=3.27$; standard deviation $(\mathrm{SD})=0.45$, and follow-up mean $=3.28 ; \mathrm{SD}=0.45$ ) were high, given a range of 1 to 4 . On a scale of 1 to 5, CollaboRATE was also high (baseline mean $=3.62 ; \mathrm{SD}=1.10$, and follow-up mean $=$ 3.63; $\mathrm{SD}=1.07$ ).

We find evidence supporting all three hypotheses (Table 2).

1. Higher baseline CollaboRATE is associated with higher PAM at follow-up $(\beta=0.04 ; 95 \% \mathrm{CI}=0.02,0.07 ; p=$ $0.001)$.

2. Higher baseline PAM is associated with higher CollaboRATE at follow-up $(\beta=0.35 ; 95 \% \mathrm{CI}=0.26,0.44$; $p<0.0001$ ).

3. The relationship between patient activation and the SDM process is bidirectional, but it is dominated by baseline patient activation, i.e., the association between baseline PAM and follow-up CollaboRATE is much stronger than the association between baseline CollaboRATE and follow-up PAM.

The path from PAM at baseline to CollaboRATE at followup (solid black) is much stronger than the path from CollaboRATE at baseline to PAM at follow-up (dashed black) (Fig. 1). Taking into account the PAM range of 1 to 4 and the CollaboRATE range of 1 to 5, the path from PAM to CollaboRATE is approximately 4 times stronger than the path from CollaboRATE to PAM.]->

Among control variables, Hispanic ethnicity was associated with lower CollaboRATE scores compared with non-Hispanic white patients $(\beta=-0.23 ; 95 \% \mathrm{CI}=-0.44,-0.03 ; p=$ 0.028 )

Results of our sensitivity analyses indicate the main results are robust to alternate analytic decisions (Appendix, Tables 46). First, in analyses restricted to patients with complete PAM and CollaboRATE data, the association between PAM at baseline and CollaboRATE at follow-up remains stronger $(\beta=$ $0.31 ; 95 \%$ CI $0.21,0.40 ; p<0.0001)$ than the association between CollaboRATE at baseline and PAM at follow-up $(\beta=0.04 ; 95 \%$ CI $0.01,0.06 ; p=0.013)$. Second, the nonlinear relationship between patient activation and SDM was not 
Table 1 Patient Characteristics at Baseline

\begin{tabular}{|c|c|c|c|}
\hline & $\begin{array}{l}\text { Analytic sample } \\
(n=122 ; ; 56 \%)\end{array}$ & $\begin{array}{l}\text { Not in analytic sample } \\
(N=954 ; 44 \%)\end{array}$ & $\overline{p \text { value }}$ \\
\hline \multicolumn{4}{|l|}{ Age, $n(\%)$} \\
\hline Under 45 & $61(5.0)$ & $95(10)$ & \multirow[t]{5}{*}{0.0001} \\
\hline $45-54$ & $151(12)$ & $127(13)$ & \\
\hline $55-64$ & $308(25)$ & $235(25)$ & \\
\hline $65-74$ & $473(39)$ & $325(34)$ & \\
\hline Over 74 & 229 (19) & $164(17)$ & \\
\hline \multicolumn{4}{|l|}{ Gender, $n(\%)$} \\
\hline Male & $526(43)$ & $459(48)$ & \multirow[t]{2}{*}{0.018} \\
\hline Female & $696(57)$ & $495(52)$ & \\
\hline \multicolumn{4}{|l|}{ Race/ethnicity, n (\%) } \\
\hline White & $520(43)$ & $376(40)$ & \multirow[t]{4}{*}{0.12} \\
\hline Hispanic & $390(32)$ & $342(36)$ & \\
\hline Black & $145(12)$ & $117(12)$ & \\
\hline Other & 167 (14) & $109(12)$ & \\
\hline \multicolumn{4}{|l|}{ Education, $n(\%)(N=2154)$} \\
\hline Less than high school & $139(11)$ & $129(14)$ & \multirow[t]{4}{*}{0.3} \\
\hline High school & $365(30)$ & $252(27)$ & \\
\hline College & $560(46)$ & $431(46)$ & \\
\hline More than college & $158(13)$ & $120(13)$ & \\
\hline Difficulty with English, $n(\%)(N=2161)$ & 204 (17) & $173(18)$ & 0.3 \\
\hline \multicolumn{4}{|l|}{ Insurance, $n(\%)(N=2064)$} \\
\hline Private & $473(39)$ & $358(43)$ & \multirow[t]{4}{*}{0.3} \\
\hline Medicaid & $21(1.7)$ & $14(1.7)$ & \\
\hline Medicare & $638(52)$ & $403(48)$ & \\
\hline Medicare-Medicaid & $90(7.4)$ & $67(8.0)$ & \\
\hline Number of comorbidities, mean (SD) & $5.9(2.6)$ & $5.5(2.7)$ & 0.0005 \\
\hline $\begin{array}{l}\text { Patient activation (PAM) at baseline, mean (SD) } \\
(N=2164)\end{array}$ & $3.27(0.45)$ & $3.26(0.44)$ & 0.3 \\
\hline $\begin{array}{l}\text { Patient activation (PAM) at follow-up, mean (SD) } \\
(N=1283)\end{array}$ & $3.28(0.45)$ & $3.32(0.40)$ & 0.8 \\
\hline $\begin{array}{l}\text { Patients' experiences of shared decision-making (CollaboRATE) } \\
\text { at baseline, mean (SD) } \\
(N=1283)\end{array}$ & $3.62(1.10)$ & $3.47(1.14)$ & 0.002 \\
\hline $\begin{array}{l}\text { Patients' experiences of shared decision-making (CollaboRATE) } \\
\text { at follow-up, mean (SD) }(N=1265)\end{array}$ & $3.63(1.07)$ & $3.16(1.13)$ & 0.005 \\
\hline
\end{tabular}

Table 2 Adjusted Cross-Lagged Panel Model Results for Patient Activation (PAM) and Patients' Experiences of Shared Decision-making (CollaboRATE) at Follow-up

\begin{tabular}{|c|c|c|c|c|}
\hline & \multicolumn{2}{|l|}{ PAM at follow-up } & \multicolumn{2}{|c|}{ CollaboRATE at follow-up } \\
\hline & $\beta(95 \% \mathrm{CI})$ & $p$ value & $\beta(95 \%$ CI $)$ & $p$ value \\
\hline PAM at baseline & $0.55(0.49,0.62)$ & $<0.0001$ & $0.35(0.26,0.44)$ & $<0.0001$ \\
\hline CollaboRATE at follow-up & $0.04(0.02,0.07)$ & 0.001 & $0.42(0.37,0.48)$ & $<0.0001$ \\
\hline \multicolumn{5}{|l|}{ Age } \\
\hline Under 44 & $0.07(-0.04,0.18)$ & 0.2 & $0.13(-0.11,0.36)$ & 0.3 \\
\hline $45-54$ & $-0.08(-0.17,0.01)$ & 0.095 & $-0.13(-0.31,0.05)$ & 0.2 \\
\hline $55-64$ & $-0.05(-0.11,0.02)$ & 0.14 & $-0.04(-0.2,0.12)$ & 0.6 \\
\hline $65-74$ & Referent & & Referent & \\
\hline Over 75 & $0.001(-0.04,0.04)$ & 1 & $0.08(-0.05,0.21)$ & 0.2 \\
\hline \multicolumn{5}{|l|}{ Race/ethnicity } \\
\hline White & Referent & & Referent & \\
\hline Hispanic & $-0.04(-0.11,0.04)$ & 0.3 & $-0.23(-0.44,-0.03)$ & 0.028 \\
\hline Black & $0.06(-0.03,0.14)$ & 0.2 & $-0.05(-0.25,0.16)$ & 0.7 \\
\hline Other & $0.03(-0.04,0.11)$ & 0.4 & $-0.06(-0.23,0.12)$ & 0.5 \\
\hline \multicolumn{5}{|c|}{ 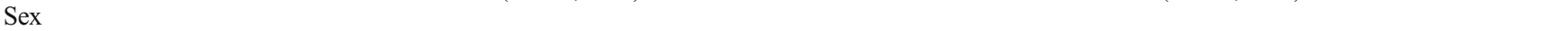 } \\
\hline Male & $-0.05(-0.1,0.001)$ & 0.054 & $-0.02(-0.12,0.07)$ & 0.7 \\
\hline Female & Referent & & Referent & \\
\hline \multicolumn{5}{|l|}{ Insurance } \\
\hline Private & $0.08(-0.01,0.16)$ & 0.065 & $0.09(-0.11,0.3)$ & 0.4 \\
\hline Medicaid & $0.04(-0.21,0.3)$ & 0.7 & $-0.14(-0.62,0.34)$ & 0.6 \\
\hline Medicare & Referent & & Referent & \\
\hline Medicare-Medicaid & $-0.01(-0.09,0.07)$ & 0.9 & $-0.05(-0.25,0.15)$ & 0.6 \\
\hline \multicolumn{5}{|l|}{ Education } \\
\hline Less than high school & $0.03(-0.06,0.11)$ & 0.5 & $-0.05(-0.35,0.25)$ & 0.7 \\
\hline High school & $-0.03(-0.08,0.017)$ & 0.2 & $-0.01(-0.14,0.13)$ & 0.9 \\
\hline College & Referent & & Referent & \\
\hline More than college & $-0.03(-0.08,0.01)$ & 0.2 & $-0.02(-0.15,0.11)$ & 0.8 \\
\hline Difficulty with English & $0.05(-0.04,0.13)$ & 0.3 & $0.03(-0.22,0.29)$ & 0.8 \\
\hline Comorbidities & $-0.01(-0.02,0.002)$ & 0.13 & $0.01(-0.01,0.02)$ & 0.5 \\
\hline
\end{tabular}

Practice fixed effects not shown for ease of presentation 


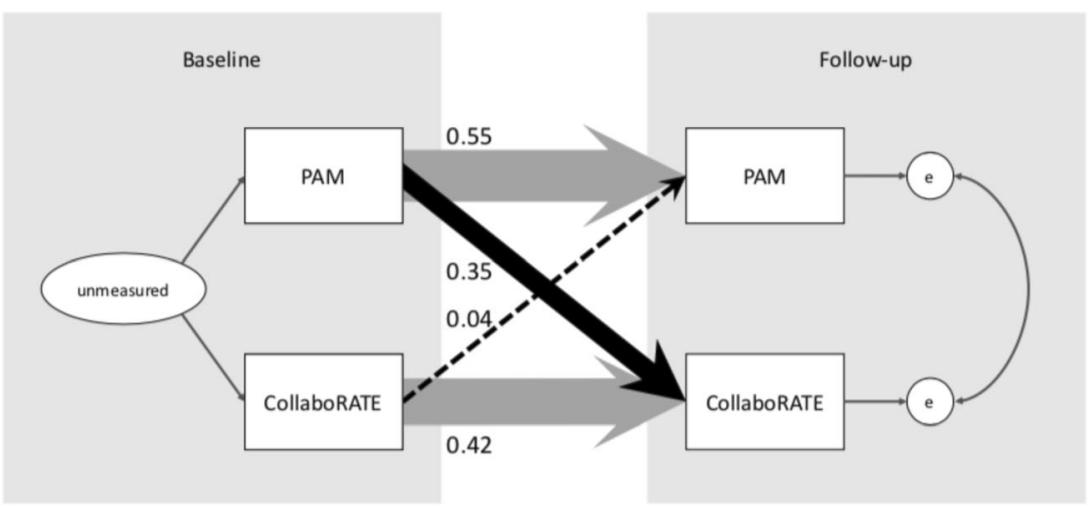

Figure 1 Cross-lagged panel model of patient activation (PAM) and patients' experiences of shared decision-making (CollaboRATE) (adjusted for patient age, race, sex, education, insurance, English proficiency, and number of comorbidities, with fixed effects for practice sites. Path magnitudes are standardized and relative to coefficients).

statistically significant. Finally, baseline PAM was significantly associated with follow-up PACIC $(\beta=0.17 ; 95 \% \mathrm{CI}=0.08$, $0.26 ; p<0.0001)$ and baseline PACIC was significantly associated with follow-up PAM $(\beta=0.07 ; 95 \% \mathrm{CI}=0.05,0.10$; $p<0.0001)$. The difference in effect sizes between PAM and PACIC, however, is not as large as the difference in effect sizes between PAM and CollaboRATE.

\section{DISCUSSION}

We found evidence supporting all three hypotheses: patients' experience of SDM is associated with greater patient activation 1 year later, patient activation is associated with patients' experience of SDM 1 year later, and the relationship is dominated by baseline patient activation.

While we examine patient activation as a precursor to SDM, prior studies have primarily focused on the impact of participatory decision-making on patient activation ${ }^{20,37}$. In an observational survey study on 1314 patients with diabetes across 25 Veterans Affairs medical centers, Heisler et al. found evidence that a more participatory decision-making style on the part of the physician can improve patient self-management, mediated by patient confidence in self-management, i.e., selfefficacy ${ }^{37}$. Similarly, in an observational survey study on 236 patients with diabetes across 5 family physician offices, a physician's participatory decision-making style was associated with patient's active participation in follow-up visits ${ }^{20}$. Our results are consistent with this prior literature as patients' experiences of SDM were positively associated with patient activation approximately 1 year later.

There is widespread interest in establishing SDM as standard practice, with some calling SDM an "ethical imperative" and "the pinnacle of patient-centered care. ${ }^{, 38,39}$ Accordingly, many decision aids have been developed to encourage patient-centered care by facilitating $\mathrm{SDM}^{40,41}$. Models of SDM have also been developed with distinct steps and examples to be used in medical education ${ }^{42}$. However, the routine use of SDM has been slow and its impact mixed ${ }^{43-46}$. Though sharing in decision-making may increase patient readiness for a more engaged role, patients are not all equally prepared to engage in SDM. Our results suggest that SDM requires personalization in its implementation.

Our results expand evidence about the connections between patient activation and patient engagement in shared medical decision-making. SDM requires the active consent of both patients and physicians ${ }^{9}$ and medical communication in the chronic care context is jointly produced by patients and physicians in multiple encounters over time. Physicians cannot simply impose a participatory decision-making style on patients. Rather, patient engagement in medical decisions shapes and is shaped by their level of activation. Our study is the first to establish the dominant importance of patient activation in this bidirectional relationship between patient activation and patients' experiences of SDM.

This finding is of practical importance to healthcare organizations with interest in improving SDM. Given limited resources, our results suggest that health systems should prioritize patient activation initiatives and target SDM interventions for patients who are relatively activated. SDM is associated with increased patient activation, but some patients may be more ready to engage than others at a given point in time. To activate patients less ready, healthcare organizations should consider less intensive patient engagement strategies. For example, patients can be coached to recognize medical decisions and identify the issues that matter most to them in making those decisions. Deen et al. developed this approach and found it to effectively improve activation even among patients with low baseline levels ${ }^{47}$. Educational interventions may also be relevant to physicians. Greene et al. found that physicians with the greatest increase in activation among their patients identified small steps for change and scheduled frequent follow-up visits. $^{48}$. These techniques were predominantly discovered by trial and error as very few physicians had received training in patient activation approaches. Given the inefficiency of trial and error and the time pressure on physicians, healthcare organizations might consider offering educational interventions to more systematically provide physicians with the skills to support their patients in managing their care. 
There are important study limitations to consider. First, crosslagged panel models have been previously used to examine causal predominance ${ }^{49-52}$, but claims of causality are not definitive, especially with only two survey waves ${ }^{35,53}$. Second, the two participating ACOs in this study may not generalize to other practices. Future research should examine whether the dominance of patient activation on SDM is consistent in other clinical settings. Third, we were unable to collect data on physician characteristics, in particular race/ethnicity. Race concordance between patients and physicians is known to impact the communication $^{45}$, which could alter these results. Fourth, patientreported experiences of SDM may reflect their relationships with clinicians other than their primary care physician, as CollaboRATE and PACIC assess patient experiences without specifying specific clinicians. Finally, recorded clinical interactions may provide more detailed information on patient activation-SDM relationship ${ }^{54}$ but such an approach is less practical for examining variation across 16 practices.

In conclusion, healthcare organizations seeking to encourage SDM will likely need to broadly invest in improving patient activation and target SDM interventions toward patients with relatively high activation. Educational interventions may hold promise for improving patient activation and, ultimately, readiness for SDM, but additional development, testing, and refinement of patient activation interventions are needed.

Acknowledgments: We would like to acknowledge the members of the study National Advisory Committee, Susan Edgman-Levitan, Massachusetts General Hospital; Jody Gittell, Brandeis University; Elizabeth Helms, California Chronic Care Coalition; Judith Hibbard, University of Oregon; Minerva Eggleston and Michael Bolingbroke, Patient Advisors for HealthCare Partners; and Linda Richard-Bey and Lawrence RichardBey, Patient Advisors for Advocate Health, as well as the study's patient advisory committees at HealthCare Partners and Advocate Health. We would also like to acknowledge Jeremy Rich, Christine Moore, and Janelle Howe at HealthCare Partners and Tom Summerfelt, Sharon Gardner, Denise Angst, and Jose Elizondo, MD, at Advocate Health for their efforts coordinating data collection efforts at the participating ACOs, Caitlin Murray of the Center for the Study of Services for patient survey administration, and Patricia Ramsay, Salma Bibi, Zosha Kandel, and Elizabet Aklyan for their invaluable assistance.

Corresponding Author: Bing Ying Poon, PhD; School of Public Health University of California Berkeley, Berkeley, CA, USA (e-mail: jessicapoon@berkeley.edu).

Funding Information This study is financially supported by the Patient-Centered Outcomes Research Institute (IHS-1310-06821) and the Agency for Healthcare Research and Quality (T32HSO22241).

\section{Compliance with Ethical Standards:}

Conflict of Interest: The authors declare that they do not have a conflict of interest.

\section{REFERENCES}

1. American Diabetes Association. Economic costs of diabetes in the US in 2017. Diabetes Care. 2018;41(5):917-928

2. Benjamin EJ, Blaha MJ, Chiuve SE, et al. Heart Disease and Stroke Statistics-2017 Update: A Report From the American Heart Association.
Circulation. 2017;135(10):e146-e603. doi:https://doi.org/10.1161/CIR. 0000000000000485

3. Meigs JB. Epidemiology of Type 2 Diabetes and Cardiovascular Disease: Translation From Population to Prevention: The Kelly West Award Lecture 2009. Diabetes Care. 2010;33(8):1865-1871. doi:https://doi.org/10. 2337/dc10-0641

4. DiMatteo MR, Giordani PJ, Lepper HS, Croghan TW. Patient adherence and medical treatment outcomes: a meta-analysis. Med Care. 2002;40(9):794-811. doi:https://doi.org/10.1097/01.MLR. $0000024612.61915 .2 \mathrm{D}$

5. Elliott WJ, Maddy R, Toto R, Bakris G. Hypertension in patients with diabetes. Postgrad Med. 2000;107(3):29-38. doi:https://doi.org/10. 3810/pgm.2000.03.940

6. McDermott MM, Schmitt B, Wallner E. Impact of Medication Nonadherence on Coronary Heart Disease Outcomes: A Critical Review. Arch Intern Med. 1997;157(17):1921-1929. doi:https://doi.org/10. 1001/archinte.1997.00440380023002

7. Grant R, Adams AS, Trinacty CM, et al. Relationship Between Patient Medication Adherence and Subsequent Clinical Inertia in Type 2 Diabetes Glycemic Management. Diabetes Care. 2007;30(4):807-812. doi:https:// doi.org/10.2337/dc06-2170

8. DiMatteo MR. Variations in patients' adherence to medical recommendations - A quantitative review of 50 years of research. Med Care. 2004;42(3):200-209. doi:https://doi.org/10.1097/01.mlr.0000114908. 90348.f9

9. Charles C, Gafni A, Whelan T. Shared decision-making in the medical encounter: What does it mean? (Or it takes at least two to tango). Soc Sci Med. 1997;44(5):681-692.

10. Moumjid N, Gafni A, Brémond A, Carrère M-O. Shared Decision Making in the Medical Encounter: Are We All Talking about the Same Thing? Med Decis Making. 2007;27(5):539-546. doi:https://doi.org/10.1177/ 0272989X07306779

11. Arbuthnott A, Sharpe D. The effect of physician-patient collaboration on patient adherence in non-psychiatric medicine. Patient Educ Couns. 2009;77(1):60-67.

12. Hamann J, Neuner B, Kasper J, et al. Participation preferences of patients with acute and chronic conditions. Health Expect. 2007;10(4):358-363.

13. Benbassat J, Pilpel D, Tidhar M. Patients' preferences for participation in clinical decision making: a review of published surveys. Behav Med Wash DC. 1998;24(2):81-88. doi:https://doi.org/10.1080/ 08964289809596384

14. Durand M-A, Carpenter L, Dolan H, et al. Do Interventions Designed to Support Shared Decision-Making Reduce Health Inequalities? A Systematic Review and Meta-Analysis. Plos One. 2014;9(4):e94670. doi:https:// doi.org/10.1371/journal.pone.0094670

15. Joseph-Williams N, Elwyn G, Edwards A. Knowledge is not power for patients: A systematic review and thematic synthesis of patient-reported barriers and facilitators to shared decision making. Patient Educ Couns. 2014;94(3):291-309. doi:https://doi.org/10.1016/j.pec.2013.10.031

16. Lorig KR, Holman HR. Self-management education: History, definition, outcomes, and mechanisms. Ann Behav Med. 2003;26(1):1-7. doi:https://doi.org/10.1207/S15324796ABM2601_01

17. Hibbard JH, Mahoney ER, Stockard J, Tusler M. Development and Testing of a Short Form of the Patient Activation Measure. Health Serv Res. 2005;40(6 Pt 1):1918-1930. doi:https://doi.org/10.1111/j.14756773.2005.00438.x

18. Mosen DM, Schmittdiel J, Hibbard J, Sobel D, Remmers C, Bellows J. Is patient activation associated with outcomes of care for adults with chronic conditions? J Ambulatory Care Manage. 2007;30(1):21-29.

19. Naik AD, Kallen MA, Walder A, Street RL. Improving hypertension control in diabetes mellitus the effects of collaborative and proactive health communication. Circulation. 2008;117(11):1361-1368.

20. Parchman ML, Zeber JE, Palmer RF. Participatory decision making, patient activation, medication adherence, and intermediate clinical outcomes in type 2 diabetes: a STARNet study. Ann Fam Med. 2010;8(5):410-417. doi:https://doi.org/10.1370/afm.1161

21. Shortell SM, Poon BY, Ramsay PP, et al. A Multilevel Analysis of Patient Engagement and Patient-Reported Outcomes in Primary Care Practices of Accountable Care Organizations. J Gen Intern Med. February 2017:1-8. doi:https://doi.org/10.1007/s11606-016-3980-Z

22. Stewart MB, Judith B., Weston WW, McWhinney IR, McWilliam CL, Freeman TR. Patient-Centered Medicine: Transforming the Clinical Method. 3rd ed: Radcliffe Publishing; 2003

23. Shortell SM, Sehgal NJ, Bibi S, et al. An Early Assessment of Accountable Care Organizations' Efforts to Engage Patients and Their Families. Med 
Care Res Rev. 2015;72(5):580-604. doi:https://doi.org/10.1177/ 1077558715588874

24. Rodriguez HP, Poon BY, Wang E, Shortell SM. Linking Practice Adoption of Patient Engagement Strategies and Relational Coordination to PatientReported Outcomes in Accountable Care Organizations Milbank Quarterly. 2019. https://doi.org/10.1111/1468-0009.12400

25. Brenk-Franz K, Hibbard JH, Herrmann WJ, et al. Validation of the German version of the patient activation measure 13 (PAM13-D) in an international multicentre study of primary care patients. PloS One. 2013;8(9):e74786. doi:https://doi.org/10.1371/journal.pone.0074786

26. Steinsbekk A. Maling av effekt av pasientopplaering [Patient Activation Measure]. Tidsskr Den Nor Laegeforening Tidsskr Prakt Med Ny Raekke. 2008; 128(20):2316-2318.

27. Maindal HT, Sokolowski I, Vedsted P. Translation, adaptation and validation of the American short form Patient Activation Measure (PAM13) in a Danish version. Bmc Public Health. 2009;9:209. doi:https://doi.org/10.1186/1471-2458-9-209

28. Rademakers J, Nijman J, van der Hoek L, Heijmans M, Rijken M. Measuring patient activation in the Netherlands: translation and validation of the American short form Patient Activation Measure (PAM13). Bmc Public Health. 2012;12:577. doi:https://doi.org/10.1186/1471-2458-12577

29. Rademakers J, Maindal HT, Steinsbekk A, Gensichen J, Brenk-Franz K, Hendriks M. Patient activation in Europe: an international comparison of psychometric properties and patients' scores on the short form Patient Activation Measure (PAM-13). BMC Health Serv Res. 2016;16:570-570. doi:https://doi.org/10.1186/s12913-016-1828-1

30. Hibbard JH, Stockard J, Mahoney ER, Tusler M. Development of the patient activation measure (PAM): Conceptualizing and measuring activation in patients and consumers. Health Serv Res. 2004;39(4):10051026.

31. Nunnally JC. Psychometric Theory. 2nd ed: McGraw-Hill; 1981.

32. Barr PJ, Thompson R, Walsh T, Grande SW, Ozanne EM, Elwyn G. The Psychometric Properties of CollaboRATE: A Fast and Frugal PatientReported Measure of the Shared Decision-Making Process. J Med Internet Res. 2014;16(1). doi:https://doi.org/10.2196/jmir.3085

33. Glasgow RE, Whitesides $\mathrm{H}$, Nelson CC, King DK. Use of the Patient Assessment of Chronic Illness Care (PACIC) With Diabetic Patients: Relationship to patient characteristics, receipt of care, and self-management. Diabetes Care. 2005;28(11):2655-2661. doi:https://doi.org/10. 2337/diacare.28.11.2655

34. Acock AC. Discovering Structural Equation Modeling Using Stata. Taylor \& Francis; 2013

35. Allen M. The SAGE Encyclopedia of Communication Research Methods. SAGE Publications; 2017.

36. Cam LML, Neyman J. Proceedings of the Fifth Berkeley Symposium on Mathematical Statistics and Probability: Statistics. University of California Press; 1967.

37. Heisler M, Bouknight RR, Hayward RA, Smith DM, Kerr EA. The Relative Importance of Physician Communication, Participatory Decision Making, and Patient Understanding in Diabetes Self-management. $J$ Gen Intern Med. 2002;17(4):243-252. doi:https://doi.org/10.1046/j.1525-1497. 2002.10905.x

38. Drake RE, Deegan PE. Shared Decision Making Is an Ethical Imperative. Psychiatr Serv. 2009;60(8):1007-1007. doi:https://doi.org/10.1176/ps. 2009.60.8.1007

39. Barry MJ, Edgman-Levitan S. Shared Decision Making - The Pinnacle of Patient-Centered Care. N Engl J Med. 2012;366(9):780-781. doi:https:// doi.org/10.1056/NEJMp1109283
40. Molenaar S, Sprangers MAG, Postma-Schuit FCE, et al. Interpretive Review : Feasibility and Effects of Decision Aids. Med Decis Making. 2000;20(1):112-127. doi:https://doi.org/10.1177/ 0272989X0002000114

41. O'Connor AM, Rostom A, Fiset V, et al. Decision aids for patients facing health treatment or screening decisions: systematic review. BMJ. 1999;319(7212):731-734. doi:https://doi.org/10.1136/bmj.319.7212. 731

42. Elwyn G, Frosch D, Thomson R, et al. Shared Decision Making: A Model for Clinical Practice. J Gen Intern Med. 2012;27(10):1361-1367. doi:https://doi.org/10.1007/s11606-012-2077-6

43. Shay LA, Lafata JE. Where Is the Evidence? A Systematic Review of Shared Decision Making and Patient Outcomes. Med Decis Making. 2015;35(1):114-131. doi:https://doi.org/10.1177/0272989X14551638

44. Ong LML, de Haes JCJM, Hoos AM, Lammes FB. Doctor-patient communication: A review of the literature. Soc Sci Med. 1995;40(7):903918. doi:https://doi.org/10.1016/0277-9536(94)00155-M

45. Cooper LA, Roter DL, Johnson RL, Ford DE, Steinwachs DM, Powe NR. Patient-centered communication, ratings of care, and concordance of patient and physician race. Ann Intern Med. 2003;139(11):907-915. doi:https://doi.org/10.7326/0003-4819-139-11-200312020-00009

46. Braddock $\mathrm{CH}$, Edwards KA, Hasenberg NM, Laidley TL, Levinson W. Informed decision making in outpatient practice: time to get back to basics. JAMA. 1999;282(24):2313-2320.

47. Deen D, Lu W-H, Rothstein D, Santana L, Gold MR. Asking questions: the effect of a brief intervention in community health centers on patient activation. Patient Educ Couns. 2011;84(2):257-260. doi:https://doi.org/ 10.1016/j.pec.2010.07.026

48. Greene J, Hibbard JH, Alvarez C, Overton V. Supporting Patient Behavior Change: Approaches Used by Primary Care Clinicians Whose Patients Have an Increase in Activation Levels. Ann Fam Med. 2016;14(2):148154. doi:https://doi.org/10.1370/afm. 1904

49. Christens BD, Peterson NA, Speer PW. Community participation and psychological empowerment: testing reciprocal causality using a crosslagged panel design and latent constructs. Health Educ Behav Off Publ Soc Public Health Educ. 2011;38(4):339-347. doi:https://doi.org/10. $1177 / 1090198110372880$

50. Burns JW, Kubilus A, Bruehl S, Harden RN, Lofland K. Do changes in cognitive factors influence outcome following multidisciplinary treatment for chronic pain? A cross-lagged panel analysis. J Consult Clin Psychol. 2003;71(1):81-91. doi:https://doi.org/10.1037//0022-006X.71.1.81

51. Cacioppo JT, Hawkley LC, Thisted RA. Perceived Social Isolation Makes Me Sad: 5-Year Cross-Lagged Analyses of Loneliness and Depressive Symptomatology in the Chicago Health, Aging, and Social Relations Study. Psychol Aging. 2010;25(2):453-463. doi:https://doi.org/10.1037/ a0017216

52. Hall JA, Milburn MA, Epstein AM. A Causal Model of Health Status and Satisfaction with Medical Care. Med Care. 1993;31(1):84-94.

53. Hamaker E, Kuiper R, Grasman R. A Critique of the Cross-Lagged Panel Model. Psychol Methods. 2015;20(1):102-116. doi:https://doi.org/10. $1037 / \mathrm{a} 0038889$

54. Roter D, Larson S. The Roter interaction analysis system (RIAS): utility and flexibility for analysis of medical interactions. Patient Educ Couns. 2002;46(4):243-251.

Publisher's Note Springer Nature remains neutral with regard to jurisdictional claims in published maps and institutional affiliations. 


\section{APPENDIX}

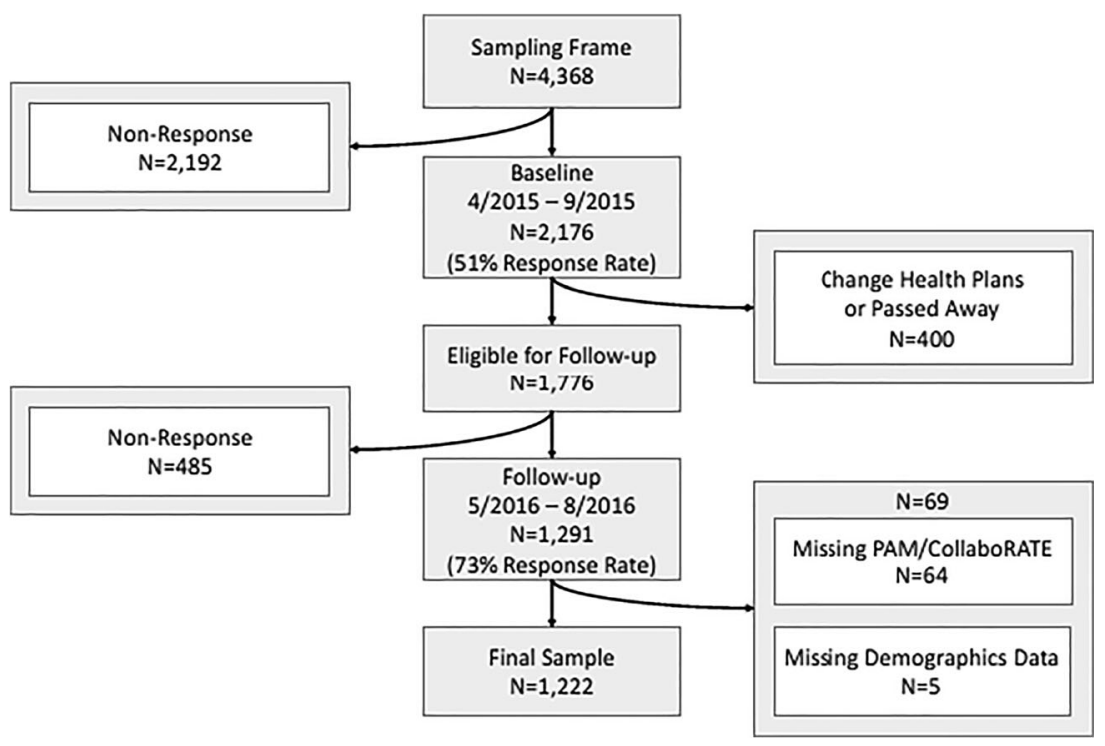

Figure 2 Cohort chart. 
Table 3 Measure Items for the Patient Activation Measure (PAM), CollaboRATE, and Patient Assessment of Chronic Illness Care (PACIC).

\begin{tabular}{l}
\hline Measures \\
PAM: For patient-reported activation, we used Hibbard's validated 13-item \\
patient activation measure (alpha $=0.92)$ from $(1)$ strongly disagree to (4)
\end{tabular}
patient activation measure $($ alpha $=0.92)$ from $(1)$ strongly disagree to $(4)$ strongly agree on the following statements.

\section{Measure items}

1. When all is said and done, I am the person who is responsible for managing my health condition.

2. Taking an active role in my own health care is the most important factor in determining my health and ability to function.

3. I am confident that I can take actions that will help prevent or minimize some symptoms or problems associated with my health condition.

4. I know what each of my prescribed medications does.

5. I am confident that I can tell when I need to go get medical care and when I can handle a health problem myself.

6. I am confident that I can tell my health care provider concerns I have even when he or she did not ask.

7. I am confident that I can follow through on medical treatments I need to do at home.

8 . I understand the nature and causes of my health condition.

9. I know the different medical treatment options available for my health condition

10. I have been able to maintain the lifestyle changes for my health that I have made.

11. I know how to prevent further problems with my health condition.

12. I am confident I can figure out solutions when new situations or problems arise with my health condition.

13. I am confident that I can maintain lifestyle changes like diet or exercise even during times of stress.

CollaboRATE: For patient-reported assessment of the shared decisionmaking process, we used Elwyn's validated 3-item CollaboRATE (alpha = 0.90 ) where patients report their providers' effort from (1) no effort to (5) every effort.

PACIC: For patient-reported assessment of their chronic illness care, we used Glasgow's validated 7-item PACIC (alpha $=0.91)$ using the following criteria from (1) never to (4) always.

1. How much effort was made to help you understand your health issues?

2. How much effort was made to listen to things that matter most to you about your health issues?

3. How much effort was made to include what matters most to you in choosing what to do next?

1. I was given choices about treatments to think about.

2. I was satisfied that my care was well-organized.

3. I was helped to set specific goals to improve my eating or exercise.

4. I was given a copy of my treatment plan.

5. I was encouraged to get a specific group or class to help me cope with my chronic condition.

6 . I was asked questions, either directly or on a survey, about my health habits.

7. I was helped to make a treatment plan that I could carry out in my daily life.

8. I was helped to plan ahead so I could take care of my condition even in hard times.

9. I was asked how my chronic conditions affects my life.

10. I was contacted after a visit to see how things were going.

11. I was told how my visits with other types of doctors, like an eye doctor or surgeon, helped my treatment. 
Table 4 Adjusted Cross-Lagged Panel Model Results for Patient Activation (PAM) and Patients' Experiences of Shared Decision-making (CollaboRATE) at Follow-up Among Patients Who Responded to All Items of the PAM and CollaboRATE Measures (Practice Fixed Effects Not Shown for Ease of Presentation)

\begin{tabular}{|c|c|c|c|c|}
\hline & \multicolumn{2}{|l|}{ PAM at follow-up } & \multicolumn{2}{|c|}{ CollaboRATE at follow-up } \\
\hline & $\beta(95 \% \mathrm{CI})$ & $p$ value & $\beta(95 \% \mathrm{CI})$ & $p$ value \\
\hline PAM at baseline & $0.56(0.50,0.63)$ & $<0.0001$ & $0.31(0.21,0.40)$ & $<0.0001$ \\
\hline CollaboRATE at baseline & $0.04(0.01,0.06)$ & 0.013 & $0.43(0.36,0.50)$ & $<0.0001$ \\
\hline \multicolumn{5}{|l|}{ Age } \\
\hline Under 44 & $0.07(-0.02,0.16)$ & 0.13 & $0.09(-0.15,0.34)$ & 0.5 \\
\hline $45-54$ & $-0.06(-0.14,0.03)$ & 0.2 & $-0.1(-0.27,0.06)$ & 0.2 \\
\hline $55-64$ & $-0.05(-0.11,0.017)$ & 0.2 & $-0.03(-0.20,0.14)$ & 0.7 \\
\hline $65-74$ & Referent & & Referent & \\
\hline Over 75 & $-0.02(-0.06,0.03)$ & 0.5 & $0.09(-0.07,0.25)$ & 0.3 \\
\hline \multicolumn{5}{|l|}{ Race/ethnicity } \\
\hline White & Referent & & Referent & \\
\hline Hispanic & $-0.05(-0.12,0.02)$ & 0.2 & $-0.19(-0.38,0.01)$ & 0.063 \\
\hline Black & $0.07(0.01,0.13)$ & 0.015 & $0.02(-0.15,0.19)$ & 0.8 \\
\hline Other & $0.04(-0.03,0.11)$ & 0.2 & $-0.06(-0.23,0.11)$ & 0.5 \\
\hline \multicolumn{5}{|c|}{ ( } \\
\hline Male & $-0.06(-0.1,-0.02)$ & 0.006 & $-0.03(-0.13,0.07)$ & 0.5 \\
\hline Female & Referent & & Referent & \\
\hline \multicolumn{5}{|l|}{ Insurance } \\
\hline Private & $0.09(0.01,0.18)$ & 0.033 & $0.10(-0.10,0.30)$ & 0.3 \\
\hline Medicaid & $0.01(-0.27,0.28)$ & 1 & $-0.22(-0.76,0.33)$ & 0.4 \\
\hline Medicare & Referent & & Referent & \\
\hline Medicare-Medicaid & $-0.04(-0.10,0.02)$ & 0.2 & $-0.03(-0.22,0.16)$ & 0.8 \\
\hline \multicolumn{5}{|l|}{ Education } \\
\hline Less than high school & $0.04(-0.05,0.13)$ & 0.4 & $-0.01(-0.36,0.35)$ & 1 \\
\hline High school & $-0.03(-0.07,0.01)$ & 0.11 & $-0.02(-0.16,0.13)$ & 0.8 \\
\hline College & Referent & & Referent & \\
\hline More than college & $-0.02(-0.07,0.03)$ & 0.5 & $-0.03(-0.16,0.10)$ & 0.7 \\
\hline Difficulty with English & $0.04(-0.05,0.12)$ & 0.4 & $-0.06(-0.32,0.19)$ & 0.6 \\
\hline Comorbidities & $-0.002(-0.01,0.004)$ & 0.4 & $0.0001(-0.02,0.02)$ & 1 \\
\hline
\end{tabular}

Table 5 Adjusted Cross-Lagged Panel Model Results for Patient Activation (PAM) and Patients' Experiences of Shared Decision-making (CollaboRATE) at Follow-up with PAM Moderated Paths (Practice Fixed Effects Not Shown for Ease of Presentation)

\begin{tabular}{|c|c|c|c|c|}
\hline & \multicolumn{2}{|l|}{ PAM at follow-up } & \multicolumn{2}{|c|}{ CollaboRATE at follow-up } \\
\hline & $\beta(95 \%$ CI $)$ & $p$ value & $\beta(95 \%$ CI $)$ & $p$ value \\
\hline PAM at baseline & $0.12(-0.81,1.06)$ & 0.8 & $-0.04(-1.26,1.19)$ & 1 \\
\hline PAM $\times$ PAM at baseline & $0.08(-0.06,0.23)$ & 0.3 & $0.12(-0.07,0.32)$ & 0.2 \\
\hline CollaboRATE at baseline & $0.15(-0.02,0.31)$ & 0.08 & $0.80(0.35,1.25)$ & $<0.0001$ \\
\hline PAM $\times$ CollaboRATE at baseline & $-0.03(-0.08,0.02)$ & 0.2 & $-0.12(-0.26,0.02)$ & 0.1 \\
\hline \multicolumn{5}{|l|}{ Age } \\
\hline Under 44 & $0.07(-0.04,0.18)$ & 0.2 & $0.12(-0.12,0.35)$ & 0.3 \\
\hline $45-54$ & $-0.08(-0.17,0.01)$ & 0.081 & $-0.13(-0.32,0.05)$ & 0.2 \\
\hline $55-64$ & $-0.05(-0.11,0.02)$ & 0.14 & $-0.04(-0.20,0.12)$ & 0.6 \\
\hline $65-74$ & Referent & & Referent & \\
\hline Over 75 & $0.001(-0.04,0.04)$ & 0.9 & $0.08(-0.04,0.21)$ & 0.2 \\
\hline \multicolumn{5}{|l|}{ Race/ethnicity } \\
\hline White & Referent & & Referent & \\
\hline Hispanic & $-0.04(-0.12,0.04)$ & 0.3 & $-0.23(-0.44,-0.02)$ & 0.03 \\
\hline Black & $0.06(-0.03,0.14)$ & 0.2 & $-0.06(-0.26,0.15)$ & 0.6 \\
\hline Other & $0.04(-0.04,0.11)$ & 0.3 & $-0.05(-0.24,0.13)$ & 0.6 \\
\hline \multicolumn{5}{|c|}{ (5) } \\
\hline Male & $-0.05(-0.10,-0.001)$ & 0.047 & $-0.03(-0.12,0.07)$ & 0.6 \\
\hline Female & Referent & & Referent & \\
\hline \multicolumn{5}{|l|}{ Insurance } \\
\hline Private & $0.08(-0.004,0.16)$ & 0.064 & $0.1(-0.11,0.3)$ & 0.3 \\
\hline Medicaid & $0.04(-0.21,0.29)$ & 0.8 & $-0.16(-0.60,0.29)$ & 0.5 \\
\hline Medicare & Referent & & Referent & \\
\hline Medicare-Medicaid & $-0.01(-0.09,0.07)$ & 0.8 & $-0.05(-0.26,0.16)$ & 0.6 \\
\hline \multicolumn{5}{|l|}{ Education } \\
\hline Less than high school & $0.03(-0.05,0.11)$ & 0.5 & $-0.05(-0.36,0.25)$ & 0.7 \\
\hline High school & $-0.03(-0.07,0.02)$ & 0.2 & $-0.01(-0.13,0.12)$ & 0.9 \\
\hline College & Referent & & Referent & \\
\hline More than college & $-0.03(-0.08,0.01)$ & 0.2 & $-0.02(-0.15,0.11)$ & 0.7 \\
\hline Difficulty with English & $0.05(-0.04,0.13)$ & 0.3 & $0.03(-0.23,0.29)$ & 0.8 \\
\hline Comorbidities & $-0.01(-0.02,0.003)$ & 0.2 & $0.01(-0.01,0.02)$ & 0.5 \\
\hline
\end{tabular}


Table 6 Adjusted Cross-Lagged Panel Model Results for Patient Activation (PAM) and Patients' Assessments of Chronic Illness Care (PACIC) at Follow-up (Practice Fixed Effects Not Shown for Ease of Presentation)

\begin{tabular}{|c|c|c|c|c|}
\hline & \multicolumn{2}{|l|}{ PAM at follow-up } & \multicolumn{2}{|l|}{ PACIC at follow-up } \\
\hline & $\beta(95 \%$ CI $)$ & $p$ value & $\beta(95 \%$ CI $)$ & $p$ value \\
\hline PAM at baseline & $0.54(0.47,0.61)$ & $<0.0001$ & $0.17(0.08,0.26)$ & $<0.0001$ \\
\hline \multirow{2}{*}{\multicolumn{5}{|c|}{ Age }} \\
\hline & & & & \\
\hline Under 44 & $0.07(-0.04,0.18)$ & 0.2 & $0.10(-0.12,0.32)$ & 0.4 \\
\hline $45-54$ & $-0.08(-0.17,0.01)$ & 0.095 & $-0.06(-0.2,0.09)$ & 0.4 \\
\hline $55-64$ & $-0.05(-0.11,0.01)$ & 0.12 & $-0.04(-0.14,0.06)$ & 0.5 \\
\hline $65-74$ & Referent & & Referent & \\
\hline Over 75 & $-0.003(-0.04,0.04)$ & 0.9 & $0.04(-0.03,0.12)$ & 0.3 \\
\hline \multicolumn{5}{|l|}{ Race/ethnicity } \\
\hline White & Referent & & Referent & \\
\hline Hispanic & $-0.05(-0.13,0.03)$ & 0.2 & $-0.05(-0.13,0.03)$ & 0.2 \\
\hline Black & $0.06(-0.03,0.14)$ & 0.2 & $0.1(-0.09,0.28)$ & 0.3 \\
\hline Other & $0.02(-0.05,0.09)$ & 0.6 & $0.13(0.03,0.22)$ & 0.007 \\
\hline \multicolumn{5}{|c|}{ 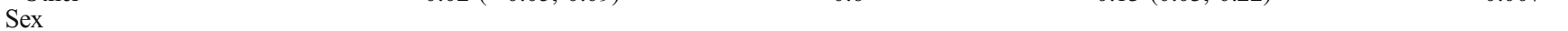 } \\
\hline Male & $-0.05(-0.1,-0.005)$ & 0.031 & $0.04(-0.04,0.12)$ & 0.3 \\
\hline Female & Referent & & Referent & \\
\hline \multicolumn{5}{|l|}{ Insurance } \\
\hline Private & $0.08(-0.002,0.16)$ & 0.059 & $0.06(-0.09,0.22)$ & 0.4 \\
\hline Medicaid & $0.03(-0.23,0.29)$ & 0.8 & $-0.07(-0.37,0.22)$ & 0.6 \\
\hline Medicare & Referent & & Referent & \\
\hline Medicare-Medicaid & $-0.01(-0.09,0.07)$ & 0.8 & $0.05(-0.13,0.23)$ & 0.6 \\
\hline \multicolumn{5}{|l|}{ Education } \\
\hline Less than high school & $0.02(-0.07,0.10)$ & 0.7 & $0.11(-0.06,0.28)$ & 0.2 \\
\hline High school & $-0.03(-0.08,0.01)$ & 0.15 & $0.03(-0.07,0.13)$ & 0.6 \\
\hline College & Referent & & Referent & \\
\hline More than college & $-0.03(-0.08,0.02)$ & 0.2 & $0.04(-0.04,0.12)$ & 0.3 \\
\hline Difficulty with English & $0.04(-0.04,0.13)$ & 0.3 & $0.08(-0.03,0.19)$ & 0.2 \\
\hline Comorbidities & $-0.01(-0.02,0.002)$ & 0.11 & $0.01(-0.01,0.02)$ & 0.4 \\
\hline
\end{tabular}

